\title{
Management of Bilateral Oehlers' Type II Dens Invaginatus in Maxillary Lateral Incisors
}

\author{
${ }^{1}$ Pranjal S Walzade, ${ }^{2}$ Sumanthini MV, ${ }^{3}$ Vanitha U Shenoy, ${ }^{4}$ Rohini P Mahajan
}

\begin{abstract}
Aim: To describe the management of type II dens invaginatus in permanent maxillary lateral incisors.
\end{abstract}

Background: Teeth affected by dens invaginatus show a deep infolding of enamel and dentine starting from the foramen coecum or even the tip of the cusps which may extend deep into the root. Dens invaginatus can be managed conservatively when it does not involve pulp and periodontal ligament. Moreover it may show a broad spectrum of morphologic variations and frequently results in early pulp necrosis if left undetected in early stages. Root canal treatment of such teeth is challenging because of the complex pulp space anatomy.

Case report: In the present case, bilateral occurrence of type Il dens invaginatus was detected in maxillary lateral incisors. Following conservative cavity preparation, 12 was restored with an adhesive restoration. However as pulp exposure was observed in 22 , it was endodontically treated.

Conclusion: Class II dens invaginatus without pulpal involvement can be treated successfully by conservative means there by maintaining the vitality of tooth. Early detection and immediate management leads to reduced tooth destruction thereby enhancing the long term prognosis.

Clinical significance: This case report will aid clinicians in the early detection and conservative management of tooth anomalies like dens invaginatus.

Keywords: Calcium hydroxide, Dens invaginatus, Glass ionomer cement, Root canal treatment.

How to cite this article: WalzadePS, Sumanthini MV, Shenoy VU, Mahajan RP. Management of Bilateral Oehlers' Type II Dens Invaginatus in Maxillary Lateral Incisors. J Contemp Dent 2017;7(2):125-129.

Source of support: Nil

Conflict of interest: None

\section{INTRODUCTION}

Dens invaginatus is a developmental anomaly that arises from invagination of enamel organ into dental papilla

\footnotetext{
${ }^{1,4}$ Postgraduate Student, ${ }^{2}$ Professor, ${ }^{3}$ Professor and Head

${ }^{1-4}$ Department of Conservative Dentistry and Endodontics Mahatma Gandhi Mission's Dental College and Hospital, Navi Mumbai, Maharashtra, India

Corresponding Author: Pranjal S Walzade, Postgraduate Student, Department of Conservative Dentistry and Endodontics Mahatma Gandhi Mission's Dental College and Hospital, Navi Mumbai, Maharashtra, India, Phone: +919503780189, e-mail: pranjalwalzade20@gmail.com
}

during bell stage. ${ }^{1}$ The invagination begins at the crown and extends into the root before its mineralization. ${ }^{2}$ Dens invaginatus has several synonyms, such as dens in dente, dentinoid in dente or telescopic tooth, pregnant woman anomaly, deep foramen cecum, tooth inclusion, and tooth within tooth. Hallett introduced the term dens invaginatus in 1953. This type of tooth anomaly was first reported by Ploquet in 1794 . He discovered this malformation in a whale's tooth. Later in 1856, a dentist named Socrates first described it in human tooth. ${ }^{3}$

Prevalence of dens invaginatus is between 0.3 and $10 \%{ }^{4}$ The permanent teeth are more frequently affected as compared with deciduous teeth by this anomaly. In permanent teeth upper lateral incisors (90\%) are most commonly affected when compared with posterior teeth (6.5\%). Often bilateral occurrence of dens invaginatus is more common. ${ }^{4}$ The classification system proposed by Oehlers ${ }^{5}$ is most popular and valuable from a clinical perspective. Oehlers categorized invaginations into three classes depending upon how far they extend radiographically into the crown and the root. They are as follows:

Type I: The invagination in type I is minimal and enamel-lined and confined within the crown and does not extend beyond the level of the external cementoenamel junction. This is the most common form of dens invaginatus occurring in 79\% cases (Fig. 1A).

Type II: The invagination in type II is enamel-lined and extends into the pulp chamber but remains within the root canal without any communication with the periodontal ligament, occurring in $15 \%$ cases (Fig. 1B).

Type III: The invagination in type III extends throughout the root up to the apical foramen and communicates with the periodontal ligament. Usually there is no communication with the pulp. Type III dens invaginatus is the least common and occurs in 5\% cases ${ }^{5}$ (Figs 1C and D).

Types I and II dens invaginatus can be managed conservatively when it does not involve pulp and periodontal ligament. When pulpal and periodontal involvement occurs, as seen most often in type III dens invaginatus, root canal treatment of invaginated teeth may present several complications. This is mainly due to the irregular shape of the root canal system(s). The large and irregular volume of the root canal system makes proper canal shaping, cleaning, and obturation challenging. The present case report describes management of bilaterally occurring type II dens invaginatus in lateral incisors. 


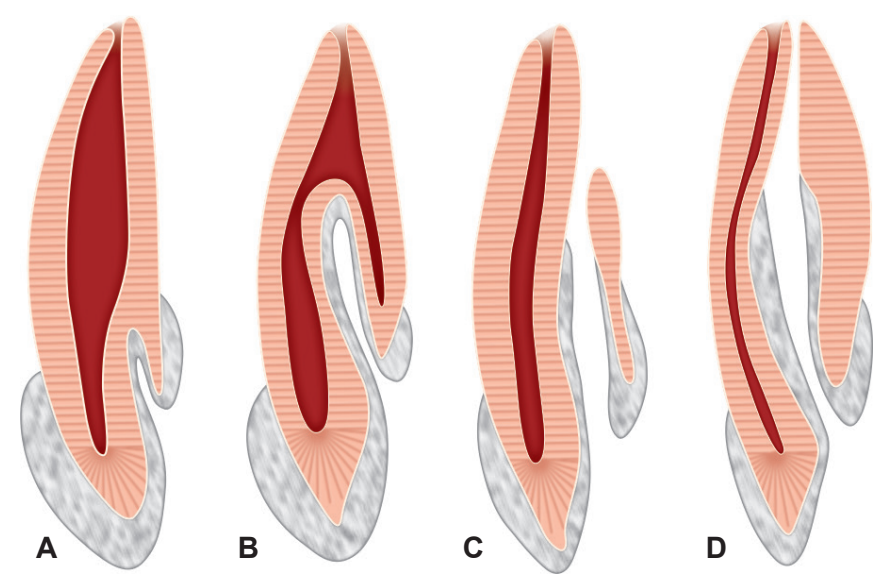

Figs 1A to D: Classification of dens invaginatus by Oehlers

\section{CASE REPORT}

A 28-year-old male patient was referred to the Department of Conservative Dentistry and Endodontics for the restoration of carious teeth and in addition desired correction of his malaligned dentition. He gave a history of trauma to the upper front tooth at the age of 14 years during which he fractured his anterior tooth. Medical history was noncontributory. On intraoral soft tissue examination, gingival recession was observed in relation to mandibular canines. Crowding was observed in maxillary and mandibular arches. On clinical examination, both the maxillary right (12) and left lateral incisors (22) had deep palatal pits which were carious and a slight enamel defect could be visualized (Fig. 2). Right maxillary lateral incisor responded within the normal range for both the thermal and electrical pulp tests, while left maxillary lateral incisor gave a delayed response. Periodontal probing depths were within the normal range. The patient was further advised for radiographic investigations.

The intraoral periapical (IOPA) radiograph (Fig. 3) shows a tear drop-shaped enamel-lined invagination

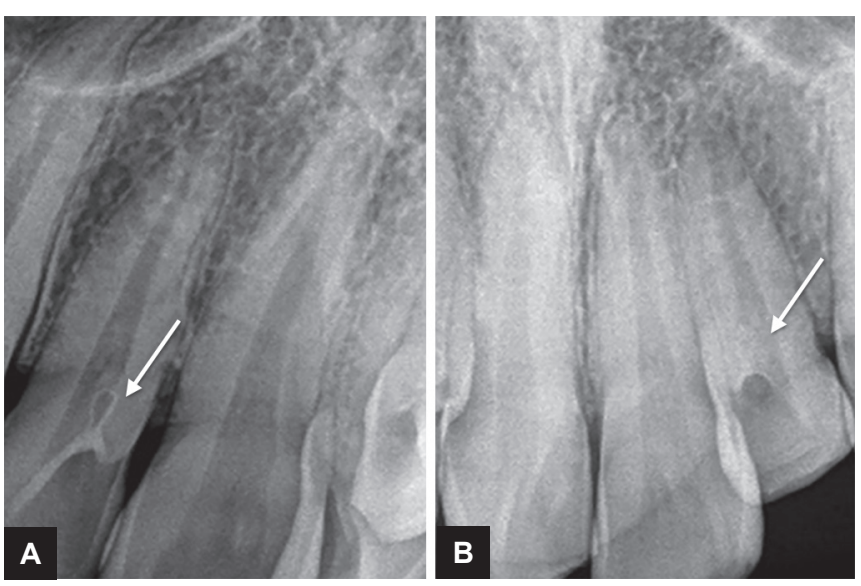

Figs 3A and B: The IOPA radiograph of (A) 12 and (B) 22. Intraoral radiographs of maxillary lateral incisors illustrate Oehlers' type II dens invaginatus. Note the deep fissure (arrow) adjacent to the pulp in both the teeth

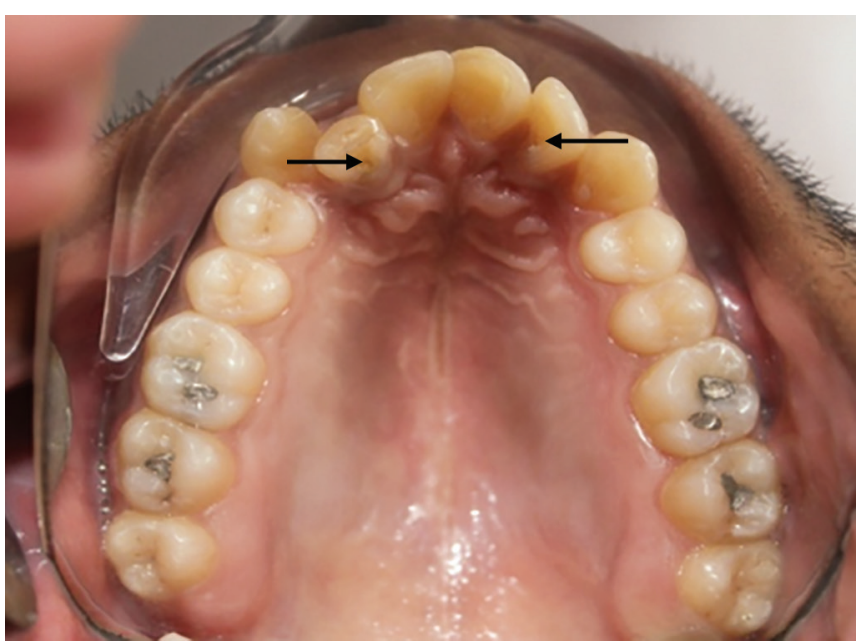

Fig. 2: Intraoral palatal photograph of patient showing deepened foramen cecum which were carious

adjacent to the pulp chamber in 12 and 22 extending to the coronal third of the root canal. This has resulted in a change in shape of the pulp chamber due to the encroachment by the invagination. There was no communication with the periodontal ligament. The radiographic features and clinical findings were suggestive of Oehlers' type II dens invaginatus.

A diagnosis of asymptomatic reversible pulpitis and asymptomatic irreversible pulpitis secondary to type II dens invaginatus with normal periapical tissues in 12 and 22 respectively, was arrived at. Hence, it was decided to conservatively restore the involved teeth with an adhesive restoration.

\section{MANAGEMENT}

In tooth number 12, under rubber dam isolation access was gained into the invagination from the palatal aspect with a high-speed handpiece and a fissurotomy bur (SS White micro STF 18013, New Jersey). The distance between the occlusal or incisal surface of the tooth and the floor of the invagination was gauged on the radiograph in order to prevent any perforation into the pulp space. Following complete caries excavation in case of 12 , it was observed that there was no pulp exposure as seen in Fig. 4.

In 12, calcium hydroxide (CH) liner (Dycal, DENTSPLY, Caulk, Milford, USA) was applied at the base of invagination and restored with a type II conventional glass ionomer cement (CGIC, Fuji II GC India Dental Pvt. Ltd.) and a protective layer of dentin bonding agent (Adper Single Bond 2; 3M ESPE) was applied and cured using a light-curing unit for 20 seconds (Fig. 5).

Similarly, 22 was also isolated under rubber dam and access was gained into the invagination. On caries excavation, pulp exposure was detected and root canal treatment was initiated under local anesthesia 


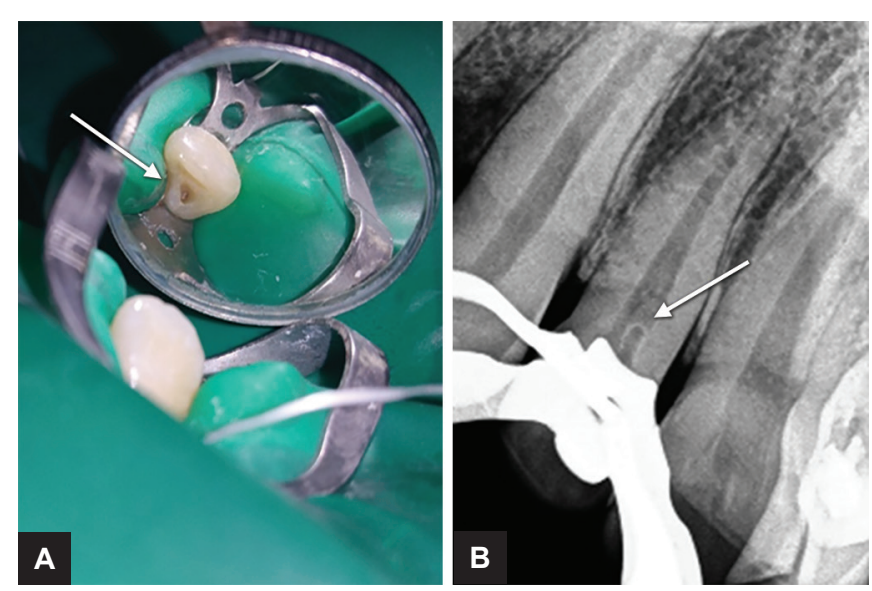

Figs 4A and B: (A) Intraoral photograph of 12 showing caries excavation and cavity preparation of the invagination; (B) Radiographic image of 12

(lidocaine with adrenaline 1:200,000). During access cavity refinement, the invagination merged into the tapering preparation (Fig. 6A). Pulp was extirpated, working length was determined using electronic apex locator and reconfirmed by radio visuography (Fig. 6B). Working length was established at $20 \mathrm{~mm}$. Canal cleaning shaping was done using step-back technique up to master apical file size number $40 \mathrm{k}$ file. The primary root canal was intermittently irrigated with $5 \%$ sodium hypochlorite (Prime Dental Products Pvt. Ltd., India), 0.9\% normal saline (Althea Pharma Pvt. Ltd., India), and chlorhexidine gluconate 2\% v/v (V Concept; Vishal Dentocare Pvt. Ltd., Ahmedabad, Gujarat, India). The root canal was obturated with gutta-percha and AH Plus Sealer (Dentsply Pvt Ltd, India) by cold lateral compaction technique (Fig. 7). Postobturation, 22 was permanently restored with type II CGIC at the orifice and the access cavity preparation with resin composite restoration (3M ESPE Filtek Z350 XT). The patient was then referred to Department of Orthodontics for further treatment.

\section{DISCUSSION}

Dens invaginatus is most often detected radiographically as the tooth remains asymptomatic unless it is
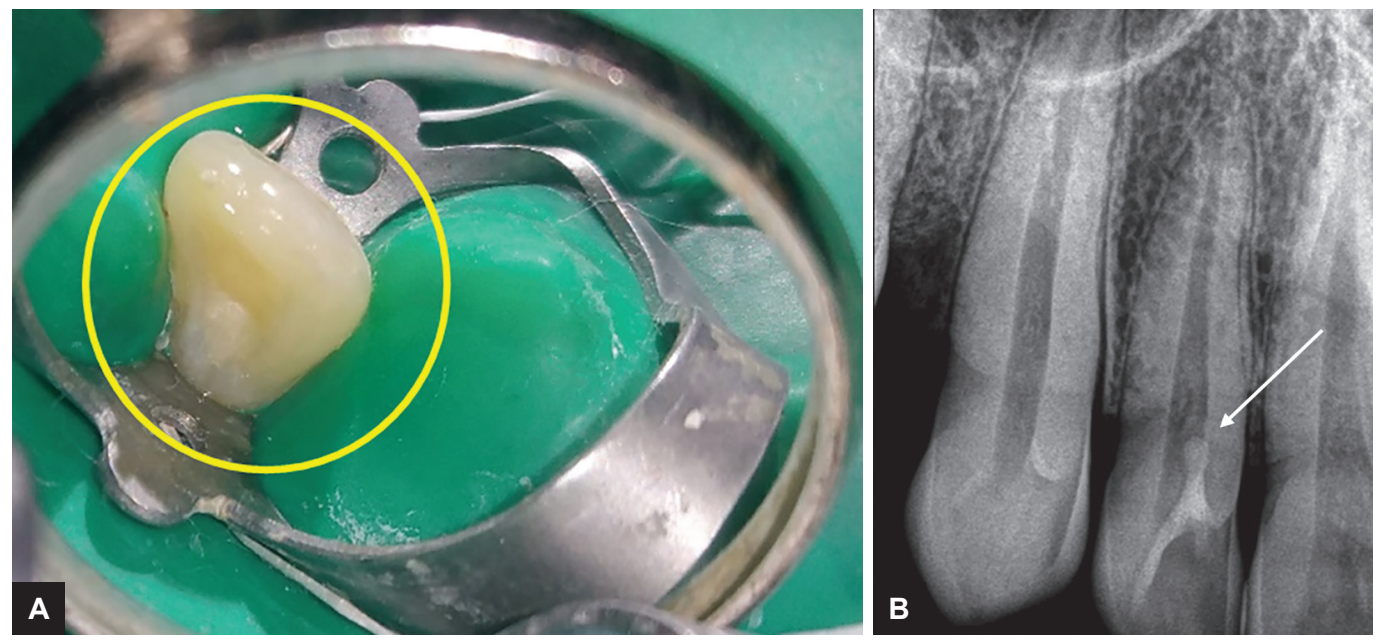

Figs 5A and B: (A) Invagination restored using $\mathrm{CH}$ and GIC w.r.t. 12. (B) Radiograph showing the restored invagination w.r.t. 12
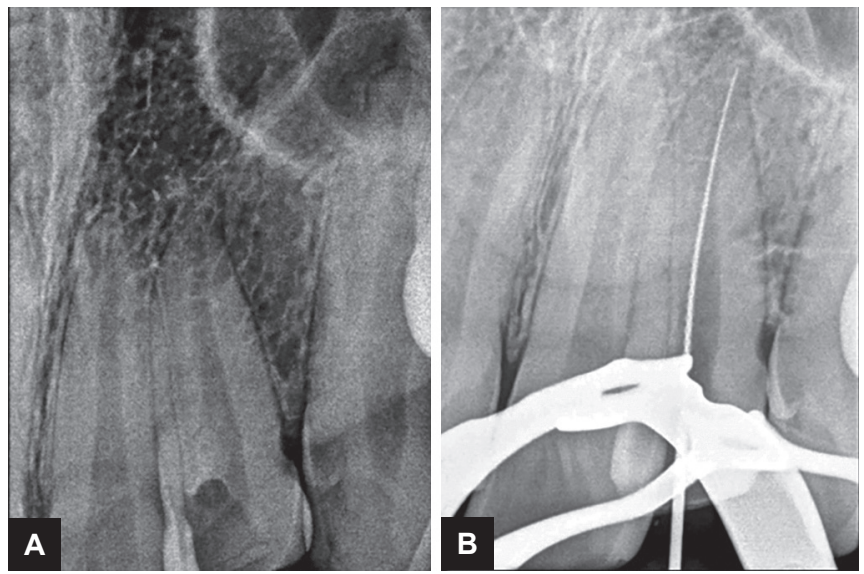

Figs 6A and B: (A) Radiograph showing communication of invagination with the pulp tissue w.r.t. 22; and (B) Working length radiograph w.r.t. 22

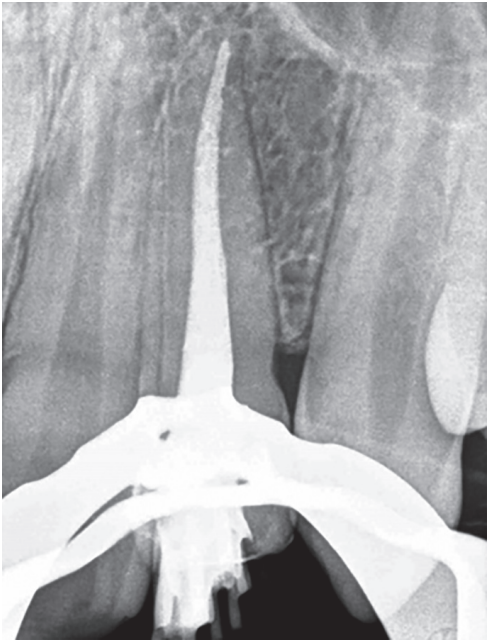

Fig. 7: The IOPA radiograph showing completed obturation 22 
infected. Clinically, the teeth may present with unusual crown morphology, such as a deep foramen cecum and widened buccopalatal width. It may be dilated peg-shaped or barrel-shaped, which may indicate the presence of dens. In the present case, a deep foramen cecum and widened labiopalatal width of the lateral incisors were observed. The dentin below the invagination may be intact without irregularities. It may also contain strains of vital connective tissue or even fine canals with communication to the dental pulp. ${ }^{6}$ The enamel is observed to have an irregular structure. Beynon ${ }^{7}$ reported hypomineralized enamel at the base of the invagination, whereas Morfis, ${ }^{8}$ in a chemical analysis, detected up to eight times more phosphate and calcium compared with the outer enamel.

According to Kronfeld's hypothesis, when these teeth erupt, the invagination will contain remnants of either dental papilla or periodontal connective tissue. These tissues may become necrotic and provide a nutrient-rich environment for oral bacteria. Types I and II dens invaginatus with deep palatal pits or foramen cecal lesions are most prone to caries, so whenever detected they should be treated as early as possible. If left unrecognized or untreated, it will lead to pulpal pathosis as seen in tooth 22 in this case (Fig. $6 \mathrm{~A})$. These teeth can be managed conservatively by prophylactic or preventive fissure sealing of the invagination before carious destruction can occur. A fissure sealing restoration and periodic evaluation is recommended.

For prophylactic or preventive restoration of the invagination, it is essential that the gingival tissues of the affected tooth should show no signs of pathosis. Pulp vitality testing, pain on percussion, and palpation of the tooth and alveolar bone must produce neither abnormal responses nor radiographic signs of periradicular pathosis. This treatment is indicated for type I and some type II forms of dens invaginatus, but not for type III forms. Hence, management of a case of dens invaginatus differs according to type manifested.

The invagination was observed to be deep in relation to 12 , hence it was not possible to use standard normal round bur to reach the floor of the invagination and achieve complete caries excavation without excessive destruction of tooth structure. In order to prepare adequate convenience form for optimum caries excavation, special fissurotomy bur was used ensuring minimal cavity preparation. Tip of fissurotomy bur is designed smaller and more conservative than $1 / 4$ round bur (Fig. 8). Its fine carbide tip does not strip quickly like thin diamonds. It allows ultraconservative pit/fissure exploration and creates an ideal cavity form for adhesive restorations. Since the cavity was in close proximity to the pulp, $\mathrm{CH}$ liner was applied at the base of invagination as a protective liner under the restorative material. Application

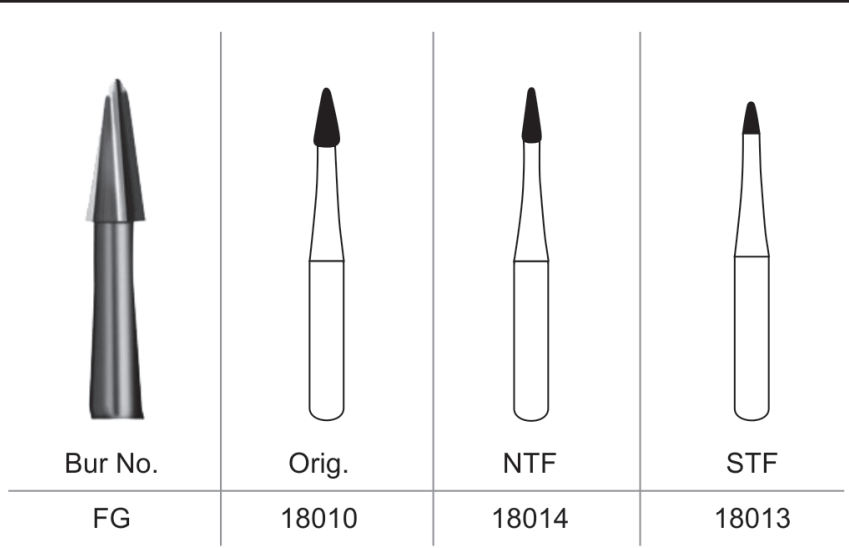

NTF: Narrow taper fissure; STF: Shallow taper fissure

Fig. 8: Fissurotomy bur

of $\mathrm{CH}$ liner stimulates formation of secondary dentin; alkaline $\mathrm{pH}$ will have bactericidal effect; it is radiopaque, rapid, and hard setting. Considering its alkalinity, biocompatibility, antimicrobial, and therapeutic properties, invagination cavity was lined using $\mathrm{CH} .{ }^{9}$

Conventional glass ionomer cement (GIC) was used to seal the invagination. The GIC was preferred relative to other materials as fluoride released from GICs to the surrounding tissues provides secondary caries inhibition and optimum abrasion resistance once it has matured in the oral environment. The benefit of fluoride released from GIC is seen in enamel adjacent to the restoration; it has also been reported in areas up to $3 \mathrm{~mm}$ away from the restoration's margin..$^{10}$ Also, GIC restorations seem to possess superior chemical adhesion to tooth structure and excellent sealing ability in comparison to other tooth colored restorative materials. ${ }^{11}$ Teeth affected with types I and II dens invaginatus have favorable prognosis. They can be managed conservatively when there is no periapical and periodontal involvement.

\section{CONCLUSION}

Knowledge of morphological variations in the anatomy of tooth structure and accurate examination of radiographs will assist in an early detection of teeth with dens invaginatus. This will aid in conservative management with minimal invasive restorative techniques, thus maintaining the vitality of tooth. However, teeth with pulpal involvement will have to be endodontically treated and recognition of anatomical variations is essential as it will help in the modifications required in the canal shaping and obturation techniques.

\section{REFERENCES}

1. Zengin AZ, Sumer AP, Celenk P. Double dens invaginatus: report of three cases. Eur J Dent 2009 Jan;3(1):67-70.

2. Sedano HO, Ocampo-Acosta F, Naranjo-Corona RI, TorresArellano ME. Multiple dens invaginatus, mulberry molar 
and conical teeth. Case report and genetic considerations. Med Oral Patol Oral Cir Bucal 2009 Feb;14(2):E69-E72.

3. Hülsmann M. Dens invaginatus: aetiology, classification, prevalence, diagnosis, and treatment considerations. Int Endod J 1997 Mar;30(2):79-90.

4. Alani A, Bishop K. Dens invaginatus. Part 1: classification, prevalence and aetiology. Int Endod J 2008 Dec;41(12): 1123-1136.

5. Oehlers FAC. Dens invaginatus (dilated composite odontome). I. Variations of the invagination process and associated anterior crown forms. Oral Surg Oral Med Oral Pathol 1957 Nov;10(11):1204-1218.

6. Piattelli A, Trisi P. Dens invaginatus: a histological study of undermineralized material. Endod Dent Traumatol 1993 Oct;9(5):191-195.
7. Beynon AD. Developing dens invaginatus (dens in dente). A quantitative microradiographic study and a reconsideration of the histogenesis of this condition. Br Dent J 1982 Oct;153:255-260.

8. Morfis AS. Chemical analysis of a dens invaginatus by SEM microanalyses. J Clin Pediatr Dent 1993;17(2):79-82.

9. Foreman PC, Barnes IE. Review of calcium hydroxide. Int Endod J 1990 Nov;23(6):283-297.

10. Kamatham R, Reddy SJ. Surface coatings on glass ionomer restorations in pediatric dentistry - Worthy or not? J Indian Soc Pedod Prev Dent 2013 Nov;31(4) 229-233.

11. Francisconi LF, Scaffa PM, de Barros VR, Coutinho M, Francisconi PAS. Glass ionomer cements and their role in the restoration of non-carious cervical lesions. J Appl Oral Sci 2009 Sep-Oct;17(5):364-369. 